Engineering Sustainability

Volume 164 Issue ES1

An 'engineer-client' framework for participation in community-scale infrastructure projects Mulligan, Tompsett and Guthrie Ice proceedings
Proceedings of the Institution of Civil Engineers Engineering Sustainability 164 March 2011 Issue ES1 Pages 35-47 doi: 10.1680/ensu.2011.164.1.35 Paper 1000022

Received 03/05/2010_Accepted 13/09/2010 Keywords: developing countries/infrastructure planning/ social impact ice

$\overline{\text { Institution of Civil Engineers }}$

\title{
An "engineer-client" framework for participation in community-scale infrastructure projects
}

1 Joe Mulligan MEng, MPhil, ACGI, Leed, AP Infrastructure Consultant, Buro Happold Consulting Engineers, New York, USA

2 Anna L. Tompsett MA, MEng, MPhil, ACGI

The Earth Institute, University of Columbia in the City of New York, USA
3. Peter M. Guthrie OBE, FREng, FICE, FCGI

Professor, Centre for Sustainable Development, University of Cambridge, UK
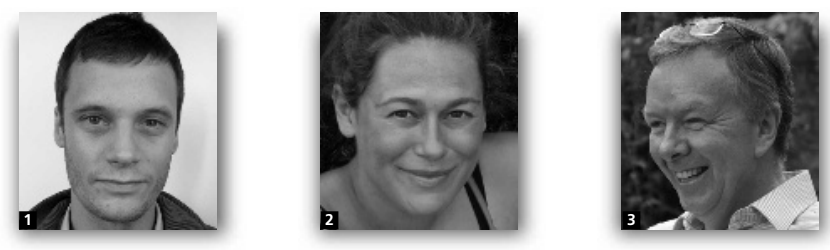

The importance of community participation in projects in the developing and developed world is widely recognised, despite considerable debate regarding what participation means in practice. In the developing world context, there is a distinct debate on how participation can achieve its stated goals of creating 'ownership' among targeted beneficiaries without becoming susceptible to elite capture or excluding marginalised groups. Projects that involve engineering analysis present a further challenge: to incorporate external technical expertise in decision-making so that project outcomes are improved, without compromising the participative process. The paper sets out a practical framework that reconciles the critical importance of early, meaningful community involvement in decision-making with the active role of the engineer as a technical adviser and facilitator. It is targeted for application in communityscale infrastructure development projects, where the community is the primary targeted beneficiary. The framework draws a parallel with a traditional engineer-client relationship, in which the client's (in this case the community's) needs and preferences drive the design process and in which final design approval rests with the client, but where the engineer plays an active role in helping to understand and interpret the client's needs and develops engineering responses through an iterative, responsive design process.

\section{Introduction}

Engineers work for a wide range of clients in their day-to-day activities - from private developers and government agencies to architects and other consultants - and develop sophisticated client-management skills through this experience. Engineers working in development projects - which are defined here as those where an underserved community is the primary targeted beneficiary of a substantially externally funded project - have historically been criticised for not fully engaging with the ideas and practice of community participation and for imposing technologies and solutions without sufficient consultation or engagement of communities in the design process. In response, engineers have sometimes adopted the language of participation, and some of the practices, piecemeal, without a clear working model of how meaningfully to incorporate participation into projects alongside a strong technical component. This paper sets out to reconcile this tension with a practical framework that combines the importance of meaningful community involvement in problem definition and decision-making, with the active role of the engineer as a technical adviser and facilitator, identifying the ways in which skills developed in more traditional 'engineer-client' relationships can be adapted for the development context.

Section 1 of the paper sets out two basic axioms on which the discussion is based: namely, that both participation and engineering have crucial roles to play in achieving successful, appropriate design in the development context. It will discuss how this generates a tension - between participation and the 
Engineering Sustainability

Volume 164 Issue ES1
An 'engineer-client' framework

for participation in community-

scale infrastructure projects

Mulligan, Tompsett and Guthrie role of external experts - and will introduce a preliminary framework for how this might be resolved, enabling engineers to translate their client-management skills into the development context while providing an overarching motivation for the application of tried-and-tested participative techniques from development practice. Finally, it will clarify the terms used and the scope of the paper. Section 2 then describes the framework in more detail, while Section 3 concludes with a discussion of some remaining unanswered questions.

\subsection{Participation matters}

The importance of community participation in projects in the developing and developed world is widely recognised. Participative approaches are used in many engineering projects at all scales and in all contexts, from stakeholder consultations for large-scale developments such as airports or rail links, to small-scale community-driven development projects, such as decentralised water or energy supply projects to serve rural villages. This paper focuses on the specific challenges of achieving successful and meaningful participation in the context of community development projects, as defined above as those where an underserved community is the primary targeted beneficiary of a primarily externally funded project. The challenges of achieving effective stakeholder participation in the context of a large-scale project with multiple stakeholders who may be both positively and negatively affected (such as the airport or rail link cases discussed above) are substantively different, and will not be addressed here.

In development projects, effective participation has the potential to reverse traditional power relationships, creating agency and voice for communities, and to yield considerable potential benefits in terms of project outcomes. Projects which achieve effective community participation are believed to increase responsiveness to people's needs, improve the delivery of goods and services and strengthen the capacity of communities to carry out future, self-initiated projects, as well as yielding less tangible benefits such as increases in social capital and 'empowerment' (Mansuri and Rao, 2004).

The assertion that projects with high levels of community participation always have better outcomes is not, however, without contention (Mansuri and Rao, 2004). Learning from past projects is difficult, because successful case studies may result from particularly effective facilitators, or a particularly well-organised community, as much as from a particular approach to community participation. Broad cross-sectional evaluations of multiple projects tend to find a strong correlation between participation and positive outcomes in development projects (e.g. Isham, et al. 1995; Sara and Katz, 1997). However, case studies (e.g. Bowen, 1986; Dasgupta and Beard, 2007; Kleemeier, 2000) often find evidence for tradeoffs between the benefits of participation (often in terms of improved responsiveness to community needs and preferences) and its disadvantages. These include the time and financial costs, both to the community and the project, of carrying out the participative process, and increased opportunities for cooptation of the decision-making process by a powerful group within the community (described as elite capture), which can result in uneven and inefficient distribution of benefits throughout the group.

A complete discussion of the pros and cons of participatory development is beyond the scope of this paper. (For a recent summary of the issues and evidence, see Mansuri and Rao, 2004.) However, despite the ongoing debate on the subject, participatory, or community-led, development is broadly accepted by governments, multilateral agencies and nongovernmental organisations (NGOs) as a core feature of their policies and approaches. Engineering organisations engaged with development - including Engineers Without Borders UK (EWB-UK), Engineers Against Poverty (EAP) and Water Aid also see participation as a central tenet of practice.

With this in mind, the remainder of the paper will take for granted the following axiom, consistent with the current position of stakeholders, from multilateral organisations to indigenous movements for decentralisation and communitydriven development:

Participation matters. Participative approaches, when effectively put in practice, can yield the following benefits: improved demand-responsiveness, improved project delivery and increases in social capital. Further, although the success of participative approaches is likely to be affected by pre-existing community characteristics, it will also be assumed that participation has the potential to yield benefits in all different kinds of communities.

\subsection{Engineering matters}

A further question is how to reconcile participation in decisionmaking, and the role of external actors bringing technological expertise to a project. This is highlighted by a study by Khwaja (2004) comparing community infrastructure projects in northern Pakistan, which found that increased community participation in non-technical decisions improved outcomes in projects, measured by the degree to which the projects were maintained several years after implementation. However, increased community participation in technical decisionmaking - those requiring information or expertise that the community is at a disadvantage to provide - actually seemed to be detrimental to project success. Anecdotal evidence from the field also supports this; a relatively recent project observed by two of the authors in northern Nigeria provided community groups with grants to build boreholes, but with no technical advice or support. The boreholes were almost exclusively not 
Engineering Sustainability

Volume 164 Issue ES1
An 'engineer-client' framework

for participation in community-

scale infrastructure projects

Mulligan, Tompsett and Guthrie functioning several months after completion of construction; they were either sited inappropriately, or unscrupulous contractors had taken advantage of the inability of the community groups effectively to monitor the quality of their work.

Reflecting this, organisations such as those listed above (EWBUK, EAP, Water Aid), also see a clear role, where appropriate, for engineering knowledge. This comprises indigenous technical knowledge, but critically also includes technical knowledge that is not locally available. Once again, the relative importance of these different kinds of knowledge can be debated extensively, but consistent with the experience of the authors, and the position of organisations working to provide technical support to communities in the developing world, a second axiom is also taken for granted:

Engineering matters. Technical skills, exemplified by those of an engineer, are critical in the successful development of a successful infrastructure scheme, although they may be (and often should be) supplemented, complemented or informed by indigenous local knowledge and experience.

\subsection{Reconciling participation with external expertise} Following from these axioms, a key question, therefore, is how to achieve effective participation - itself an open question while also incorporating technical knowledge and design skills from outside the community. This means enabling true voice and agency for the community -characterised by an effective transmission of information concerning local needs and preferences; active involvement in, and power within, the decision-making process; and adequate representation for all groups within the community - while retaining a clear, active, but not dominant, role and agency for the engineer.

The paper sets out a framework describing well-defined roles for external 'experts' and 'community beneficiaries,' with a means for mutually respected input from both parties and a structure of decision-making responsibility, which aims to resolve this tension. The framework draws on a parallel between the traditional engineer-client relationship and the more complex relationship between the engineer, funding organisation and community in the development context to demonstrate how skills developed in the traditional context can be transferred - but critically, not wholesale.

The framework locates participatory processes within a project delivery process that maximises opportunities for incorporating external technical expertise and local knowledge and preferences, while ensuring that the community retains meaningful control over final decision-making. This component - control over decision-making - is believed by the authors to be essential in avoiding a situation where participation is paid only lip service, or merely used as a justification for previously established goals and objectives. The paper will recognise that, in many cases, a process must be undergone to allow a 'community' (a heterogeneous, diffuse group with complex internal social and political structures) to take decisions collectively that result in fair and equal dividends.

\section{Framework description}

\subsection{Definitions and scope}

Having introduced the broader context of the debate, it is important to define some of the key terms that will be used in discussing the framework proposed in this paper.

\subsubsection{What is participation?}

Participation is considered here to constitute the active involvement of members of a community in project design and implementation. It will be considered to have two requisite elements: information gathering, and participation in decisionmaking. It may also involve the participation of community members in implementation, operation or maintenance.

When evaluating the appropriateness of participative methods, a concern is the balance between the additional time and financial costs involved (which may be significant) and the benefits that result. Throughout this paper, it will be assumed that the net balance of these benefits is positive, although the framework does explicitly set out to propose an efficient - and therefore cost-minimising - structure for participation.

\subsubsection{What type and scale of projects?}

This paper addresses participation in the context of what will be referred to as community-scale infrastructure developments. These are relatively small-scale projects where a 'community' is the primary targeted beneficiary. Examples might include: water supply options for rural settlements; a network of improved earthen roads to connect a group of rural villages to a main road; a flood retention structure in an urban informal settlement; a decentralised energy system to serve a community hospital. This constraint on scale is designed to limit the discussion to a distinct context where the framework is most appropriate. Infrastructure projects that are networked by nature at a wider geographical scale and which by definition have multiple groups of beneficiaries (e.g. inter-city road construction, grid extensions, large-scale dams to provide energy at a regional scale) are not directly addressed here.

\subsubsection{What is 'community'?}

Since this paper defines community-scale infrastructure development projects as those that have a 'community' as primary beneficiary, it is necessary to define what is meant by the term in this context. Community-scale infrastructure development 
Engineering Sustainability

Volume 164 Issue ES1
An 'engineer-client' framework

for participation in community-

scale infrastructure projects

Mulligan, Tompsett and Guthrie projects typically provide for a group of people or settlements defined by a geographical boundary. Given this, the paper will use 'community' to describe a group of people living or working in a geographically defined area.

These geographical limits may, or may not, coincide with other ethnic, religious, political, administrative or socioeconomic boundaries. Where geographical and other boundaries do not coincide, the geographical limits will not map to a cohesive 'community' in the sense of a unified, homogeneous group. An informal settlement may, for example, be defined by geographical boundaries, characterised by a set of socioeconomic, religious or ethnic characteristics that are very different from its surroundings, but contain significant heterogeneity across those characteristics. Communities are also, necessarily, complex entities, composing many different individuals and subgroups, all with unique economic, political and social power structures and relationships. A rural village may comprise many different clans and families, all of whom stand to gain differently from infrastructure development.

The framework proposed in this paper will therefore aim to take into consideration these inherent complexities, recognising the importance of local decision-making structures, but avoiding the presumption that these local decision-making structures reflect completely the preferences of all groups within the community.

\subsubsection{What is 'external expertise'?}

External expertise describes the type of knowledge that is not available within the community, exemplified by the knowledge provided by an engineer (or by a health professional). Examples from engineering could include water treatment technologies or road construction techniques not practiced within a community that require a certain level of technical understanding.

It is worth reiterating the belief of the authors that this type of external knowledge is complementary to local, indigenous knowledge, and that the framework set out here explicitly aims to create opportunities for the design process to incorporate both. Further, the range of an engineer's skills will likely not extend to some of the artisanal skills which might be available locally - such as bricklaying or drilling - which will have a fundamental role to play in ensuring the success of a small-scale infrastructure project. The engineer must also come with the humility to integrate their own professional knowledge with the widespread and subtle skills of artisanal trades, and to recognise the central importance of local 'know-how' in project delivery.

\subsection{Project roles}

The framework outlined in this paper is based on the central idea that there are key similarities between the traditional engineer-client relationship and the engineer-community relationship in community-scale infrastructure development projects. As a result, the skills developed in interacting with clients in traditional engineer-client relationships are relevant and useful in managing the engineer-community relationship in the development context. Drawing a parallel between these two sets of interactions allows us to consider how the dynamics of these relationships play out over the various stages of a project with the goal of informing the thinking of engineers working on community-scale infrastructure development projects with respect to improving the effectiveness of participatory processes.

In engineering projects, engineers interact with public and private clients. This interaction represents the primary relationship through which engineering services are delivered and project outcomes are determined. Through this process engineers may also interact with communities (who may be targeted beneficiaries or equally be adversely affected by projects) through a wide range of consultation processes, sometimes directly and sometimes indirectly through the client body. Traditionally decision-making responsibility rests with the client, even if that client is essentially acting on behalf of a community. Where a community is the ultimate beneficiary of a project, decision-making authority for the project is typically devolved to a body that acts as the client - often a government body, but sometimes a community-based organisation. These bodies may be imperfect, but critically they are either preestablished or established separately to the design process: the mechanism by which needs and requirements are communicated and met is clearly established, and decision-making structures are already defined.

In community-scale development projects that adopt a participative approach, in contrast, there are potentially several additional complications. The first is the presence of the funding organisation - government, an NGO, or a multilateral aid agency - which takes on part of the role that the client plays in the traditional setting, being in control of high-level budgeting and defining at least some of the early project specifications. The community itself then must also play the role of the client in some stages of the project. However, the decision-making structures encountered in the traditional context may not exist, may not be well-functioning or may not be representative of all the groups within the community.

Figure 1 compares simplified/idealised engineer-client relationships in the 'traditional' and 'development' contexts. Table 1 subsequently outlines some of the important similarities and differences between the two settings.

Of course, clients in a traditional setting may also not be as unified and internally consistent as portrayed in Table 1 and 


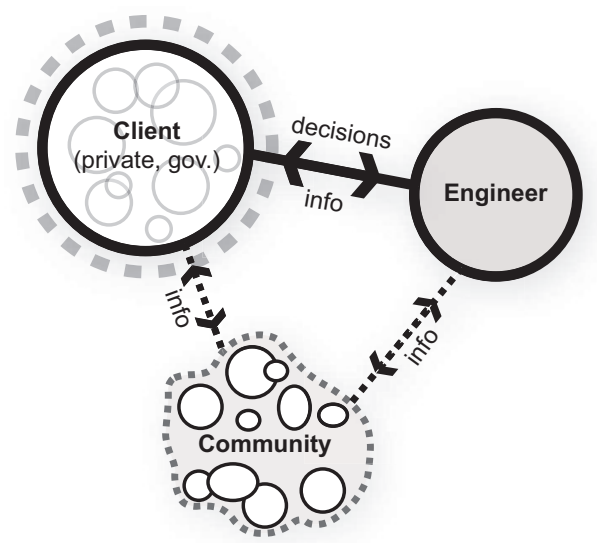

(a)

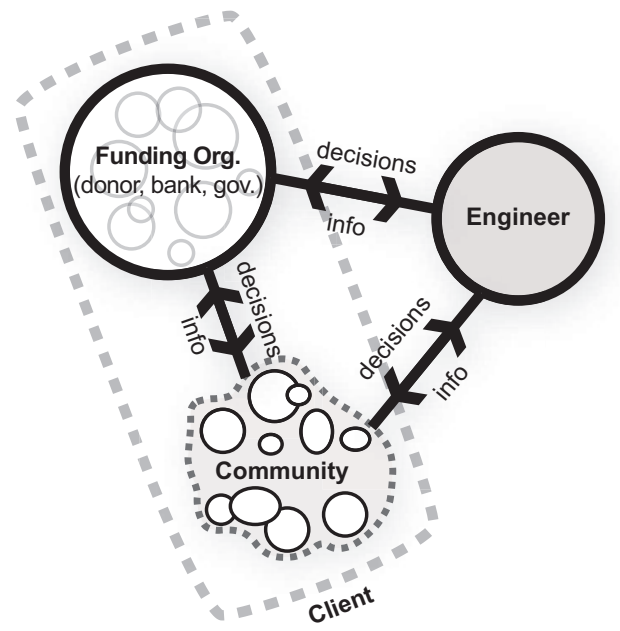

(b)

Figure 1. Comparative diagram of simplified/idealised engineerclient relationships in (a) 'traditional' and (b) 'development' contexts

Figure 1 - and subsequently engineers will already be familiar with the need to understand and work with multiple opinions and points of view - but they are likely to be relatively more so than a heterogeneous community.
The differences between the participatory engineer-community relationship and the traditional engineer-client relationship highlight some of the challenges encountered in successfully implementing a participative process. The framework described

\section{Traditional engineer-client relationship}

Who is the client? Owner/developer/government agency/other consultant

Coherent set of objectives

Clear power-structure and hierarchy within client

Client has full control over budget

Who is the engineer? process
Selected by the client, typically through a competitive Employed by the funding organisation

Contracted directly to the client

Brings a specific set of skills (including technical Brings a specific set of skills (including technical knowledge) not otherwise available to the client knowledge) not otherwise available to the community or the funding organisation

Specific scope of works; but engineer must actively Scope of works defined at broad level; engineer must participate in fully understanding client requirements actively participate in defining community-specific scope of works

Table 1. Similarities and differences between the roles played in the traditional engineer-client relationship and the participatory engineer-community relationship 
Engineering Sustainability

Volume 164 Issue ES1
An 'engineer-client' framework

for participation in community-

scale infrastructure projects

Mulligan, Tompsett and Guthrie in this paper aims to provide a guiding structure for the design of solutions to these challenges.

\section{3 "Engineer-client" framework}

Figure 2 shows an outline of the proposed 'engineer-client' framework. The framework uses a simplified project life cycle structure of five stages: project definition; project design; project implementation; operation and maintenance, and evaluation. While these stages are portrayed linearly, iterative components are of course always key, and are shown using arrows.

The key stages in the participatory process are shown in parallel with their equivalents in the traditional project evolution, and key differences are highlighted. The remainder of this section discusses the important stages in the process, highlighting the similarities and differences across the two settings. Section 2.4 will then go on to discuss the key elements of the participative process identified here, focusing in particular on the inherent complexities of the process which must be undergone for a complex, diverse community to act as an effective 'client'.

\subsubsection{Project definition}

The most immediate difference between the two settings is that, while the community is the targeted beneficiary, the general focus of the project and major budget constraints are almost always set at a higher level than the community. Even under

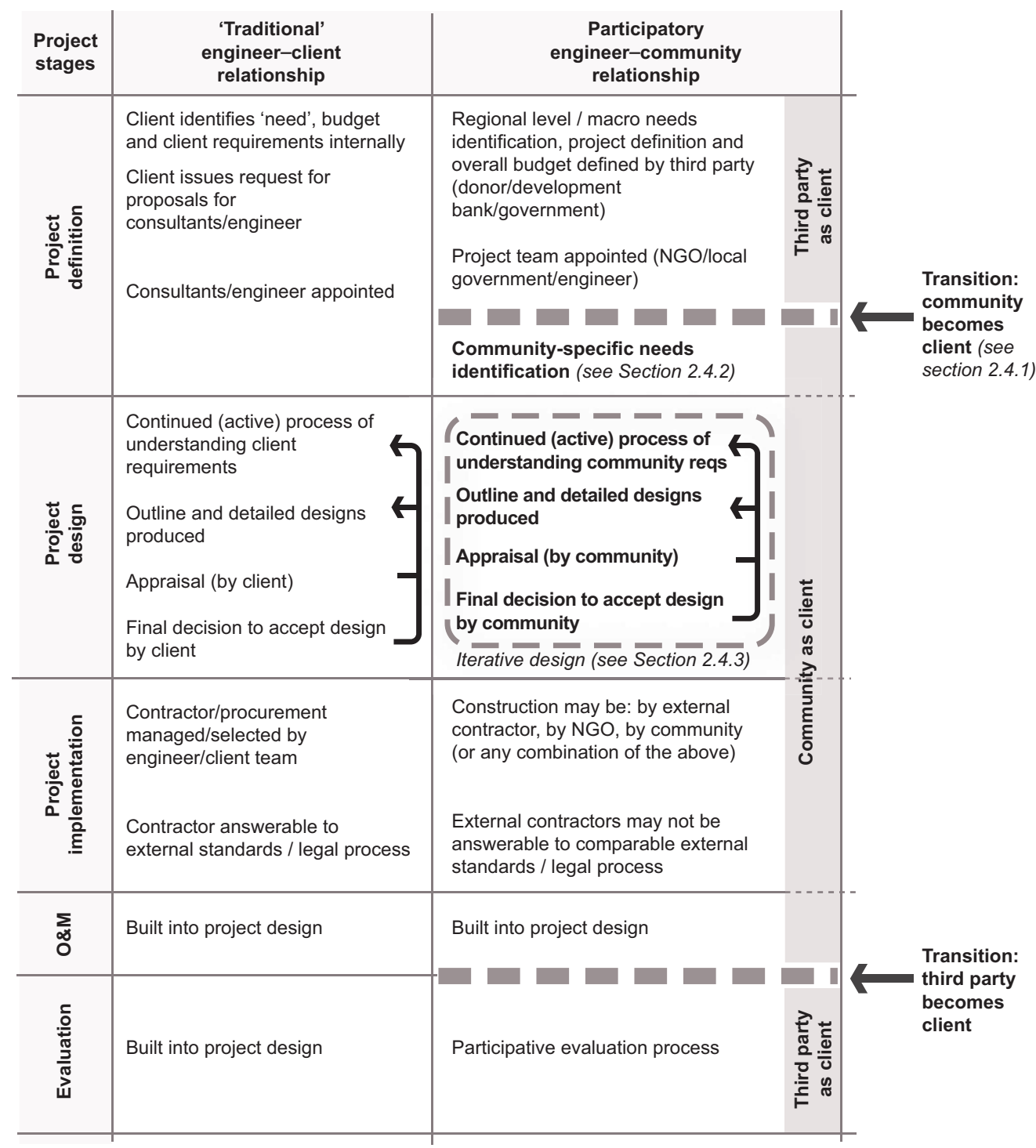

Figure 2. Proposed 'engineer-community' framework 
Engineering Sustainability

Volume 164 Issue ES1
An 'engineer-client' framework

for participation in community-

scale infrastructure projects

Mulligan, Tompsett and Guthrie the 'social fund' model, where a community is given a budget to manage themselves, the menu of acceptable projects is defined previously, along with the constraints on the available budget. The only exception to this would be where a project is entirely conceived and funded within in a given community, which would certainly preclude the need for governmental or NGO involvement. Since engineers are typically employed or assigned to a project at this early stage, the initial client is not usually, from the engineer's perspective, the community itself. This implies that a transition must be undergone through which the community takes on the role of client. (This structure may also mean that the engineer can be viewed with some scepticism or mistrust - since the community has not chosen or employed the engineer directly themselves - especially where the community's relationship with the funding organisation (e.g. local government) is itself ambivalent.)

While the general focus of the project is likely to be established prior to the direct involvement of the specific community, projects will typically require further definition, based on the community's particular needs and preferences. For example, safe drinking water projects will require the assessment of hydrogeological conditions in the area, as well as social information about population, demographics, health and existing water use patterns. A second key stage in project definition, therefore, is community-specific needs assessment, requiring a participative approach to information gathering.

\subsubsection{Project design}

As any engineer will recognise, the design process is intrinsically iterative; design proposals of increasing levels of detail are put forward and then adapted in response to the client's requirements. Good designers are also typically conscious of the benefits of active engagement in trying to understand and respond to the nuances of a client's requirements, which may not be completely articulated from the beginning. This process should be paralleled in a participatory infrastructure design project, with opportunities for design review and approval built in. Throughout this process it will also be important to facilitate engagement with the artisans and builders who will be involved in project implementation, and who will bring locally relevant practical and technical experience to the project.

In presenting design options to the community, the onus will be on the engineer to communicate the advantages and disadvantages where a particular technical approach is proposed, both in language that is comprehensible to the community, and in terms which relate those advantages and disadvantages to the community's needs and requirements. Overall this process should not be construed as the engineer 'imposing' an externally selected technology on the community; on the contrary, it is exactly the same process that must be undergone when proposing a specific design strategy or technology to a commercial client. The difference is that the client in a commercial project always has the final say in deciding whether to accept or reject a particular strategy; it is therefore argued that the same should be true in participative development projects, and that a key component of participation is assigning final decision-making authority to the community itself.

An engineer in the traditional setting is answerable throughout to external standards and laws regarding construction standards, the environment, and health and safety. Similarly, an engineer in a development context has a comparable responsibility both to understand the social, economic and environmental context, and to ensure that design solutions avoid adverse consequences that are either unforeseen by the community or that affect others in the area.

\subsubsection{Project implementation}

In the traditional engineer-client setting, responsibilities are fulfilled by providing design drawings and construction administration services to ensure that a contractor is able successfully to complete construction. An important difference in a development context is that contractors may not have the same technical capacity or may not be answerable to comparable standards, or to effective legal or criminal sanctions. The engineer's responsibility to the community therefore often extends to providing an additional technical and administration component in monitoring and closer engagement in construction and implementation, ensuring both build-quality and transparency. If community labour is used, as part of the beneficiary contribution to the project, it is likely to be part of an engineer's responsibility to actively plan and supervise these phases of construction.

\subsubsection{Operation and maintenance}

Good design, in any context, always considers the client's needs, capabilities and responsibilities in terms of operation and maintenance. Emphasis must be placed on operation and maintenance requirements throughout the project definition and design phases. Proposed designs must be commensurate with the capacity of the community - in terms of skills, time and resources - to meet operation and maintenance commitments, and the community's acceptance of a design solution must be explicitly linked to their acceptance of those commitments.

In particular, past project experience (e.g. Kleemeier, 2000) suggests strongly that participative approaches in early phases of project development do not guarantee the successful operation and maintenance of design solutions. Participation does not and will not compensate for a lack of consideration 
Engineering Sustainability

Volume 164 Issue ES1
An 'engineer-client' framework

for participation in community-

scale infrastructure projects

Mulligan, Tompsett and Guthrie on the part of donors as to how operation and maintenance costs are to be met.

\subsubsection{Evaluation}

In the development context, the engineer is once again answerable to the funding organisation as client during the evaluation phase. However, feedback from the community/ beneficiaries is essential to improving future project design. Participative information-gathering techniques (such as focus groups and semi-structured interviews) may be useful at this stage of the process. Systems for participatory monitoring and evaluation have successfully been tested and implemented in the past and may provide useful references for design of this phase of the project (e.g. FAO, 2003; Vernooy et al., 2003).

\subsection{Key elements of participative process}

The framework highlights three key elements of the participative process, which are further discussed in this section. Established techniques from participative development, where they exist, can be utilised where appropriate within the context of this framework. Some of these techniques are identified below, under the relevant element, along with references for further information. For further case studies and descriptions of different methods or techniques see, for example, World Bank (1996)

\subsubsection{Transition of community to client}

This is the single most important stage in the process of achieving successful community participation in project development. The framework set out here has aimed to describe clearly the fundamental problem inherent in the involvement of a community as a whole in a decision-making process; how does a heterogeneous group of individuals and factions act coherently to take decisions that benefit the common interest?

This is an extremely difficult problem, and while this framework cannot offer a universally applicable solution to this problem, a clear setting out of objectives is useful in looking for a local solution. Essentially, a structure must be identified or created by which the community can take decisions, or act as a client. There are fundamentally two possible strategies to take: identifying and utilising traditional or local decisionmaking structures, or creating a democratic, representative structure through the election of community representatives to a panel (who could play a role in providing feedback through the iterative stages of the design process). Both of these options have drawbacks. Local decision-making structures may perpetuate or reinforce local inequalities and power relationships and facilitate elite capture of the project, or simply poor decision-making if the needs of the poor or less powerful are not well represented through these channels. However, creating new management structures may disrupt or alienate traditional decision-making bodies, or be interpreted as the external imposition of outsider social systems or values.

The choice of the right decision-making structure must therefore be strongly informed by local conditions. As a general principle, it is essential to identify and understand local decision-making structures, and work in partnership with local decision-makers and elites, even if the final decision-making structure does not simply rest with these groups. Influential, well-connected or highly motivated individuals within the community may play an important role as change agents throughout this transition. Full community-wide votes may also have a role to play at various stages of the design process, and potentially also in deciding how the community is to be represented in interim decisions. The engineer, as an external agent, can have a role to play in deciding what decision-making structure is appropriate where existing internal inequities can only be addressed through an externally imposed change in representation in decision-making.

The scale of the project is likely to influence the best decisionmaking process; it may be possible to take relatively simple decisions, such as the location of a communal well, by vote at full participation community meetings. However, more complex projects, such as the routing of an improved earthen road through a network of villages, will require the identification or appointment of community representatives who can liaise with engineers throughout the design process.

None of these guidelines offers a final solution to this problem, and the choice of decision-making structure will almost always imply trade-offs between different outcomes. Keeping the objective clearly in mind - to enable the community to take decisions that are most representative of the community's needs as whole - may help to focus the process throughout this stage. It is also perhaps worth reiterating here the parallel with cases where the government represents the people as a client on a public infrastructure project; there are a great many flaws in this process, and it is deeply imperfect, but where systems of governance are established, it is nonetheless broadly accepted. To paraphrase Winston Churchill, in participation, as in government, perhaps the best that can be aspired to is to find a system that is no worse than any of the others that have been tried.

A final consideration is that the overall project budget is likely to be (at least partially) externally imposed. Once community representatives and participants in the decision-making process have been established, the financial constraints of the project through the whole life cycle (including operations and maintenance) must be clearly explained and emphasised. Acceptance and understanding of the budget constraints are 
Engineering Sustainability

Volume 164 Issue ES1
An 'engineer-client' framework

for participation in community-

scale infrastructure projects

Mulligan, Tompsett and Guthrie essential in enabling the community to choose the best option available within the budget, as would a commercial client.

\subsubsection{Community-specific needs identification}

Regardless of how the community is to be represented in the decision-making structure, it is unlikely that these representatives - whether drawn from traditional leadership or elected - will be able to provide sufficient information fully to define community needs and preferences at the project definition stage. The type of information gained through this process is likely to be largely social and economic in nature populations, needs, customs and so on - and will be supplementary to more technical information gathering: that is, hydro-geological conditions, soil profiles, climate data and so on. In addition communities can often provide supplementary technical information, for example on climate variation with time and seasons or local flooding patterns.

Understanding the subtleties of community needs, values and social patterns is critical to appropriate project design. A village borehole project in Afghanistan - which eliminated the need for a 2-hour walk to collect water - was repeatedly vandalised; travelling to the old borehole had provided an important social function of creating an opportunity for women to socialise, which the new borehole had taken away. If this need had been recognised earlier, it is possible that the project could have found some other way to meet this social need while still reducing the burden of time and physical labour required in water collection.

Participative information-gathering techniques that reach out to the broader community are likely to be required. Methodologies that may be useful include participatory rural appraisal (Anyaegbunam et al., 2004) and participatory poverty assessment (Norton et al., 2001). Specific elements drawn from these methodologies may also be useful as standalone techniques, such as social mapping (see, for a relevant example, Welle, 2006). However, if the project timetable and budget permit, simply spending time in a community observing, asking questions and participating in local life often provides unexpected insights that formal informationgathering processes may overlook.

\subsubsection{Iterative design process}

As in any context, the objective of an iterative design process is to optimise the design solution, both from a technological point of view and to best respond to community needs and preferences. As the design goes through several iterations, it may be preferable to use community representatives and panels to provide feedback on the design at interim stages. Establishing a process like this is efficient in terms of time, but also enables individuals to build up relationships, facilitating effective communication despite barriers of language, culture and differences in technological expertise. This process of communication may, however, be challenging for both engineers and community. Technical language and drawings are unlikely to be sufficient for communication of ideas and proposals; other strategies such as the use of threedimensional models, demonstrations, or visits to areas where similar technologies have been implemented may be helpful. Using multiple strategies to communicate the same idea may help to identify areas of misunderstanding and may contribute to building up a common language of communication, whether verbal or visual.

While the value of externally available technological expertise is key - and indeed is a prerequisite for the need for an external expert - the design process can and should incorporate local technologies, traditions and approaches, as well as local knowledge of the environment. This serves to underline the reality that, while the knowledge of an external expert is required, the expert needs to seek out and incorporate locally available skills and expertise, and in doing so, ensure that the process of knowledge transfer is in fact a process of knowledge exchange. As already argued, financial constraints, as well as operation and maintenance requirements, must be clearly described and understood throughout this process. It is also key that the full range of options is clearly articulated to the community from an early stage; previous studies have found that communities are often not aware of all the options open to them, despite project design that aims to offer a range of alternatives (Sara and Katz, 1997).

Ensuring that the community remains the final arbiter of acceptance of the design - and is fully aware of and able to use this right - is key in creating a decision-making structure in which engineers can actively promote what they judge to be the best technological solutions, and also where the community is protected from external imposition of design solutions, and still retains less tangible benefits of participation in decision-making; that is, 'empowerment' or increases in social capital. A largescale community vote on the final design solution proposed could be considered as a mechanism for this to take place.

\subsection{Examples in context}

While this framework is informed by experience on participatory projects, it has never been explicitly implemented in project design, and as such should be seen as an initial attempt to conceptualise a potential resolution to the tensions between participation and external expertise. However, the following are examples of how a participative process might be designed using the framework set out in this paper. The case studies are based on real-life experiences in Nigeria and Bangladesh (research undertaken by Madajewicz et al., National Science Foundation Human and Social Dynamics research project 'Decentralisation and local public goods: how does the allocation of 
Engineering Sustainability

Volume 164 Issue ES1
An 'engineer-client' framework

for participation in community-

scale infrastructure projects

Mulligan, Tompsett and Guthrie decision-making authority affect provision?' (in progress)). However the participative processes described are not those actually implemented but rather a suggestion for how a fully integrated participative process might have been applied in those contexts.

\subsubsection{Rural road and river crossing design and construction, Nigeria}

Context. A community of several thousand people is distributed in a number of villages on one side of a seasonal river that, when flooded, cuts the community off from access to the inter-city road for several months each year. The villages are connected to each other and the inter-city road by a network of very basic earthen roads in very poor condition, fording the river at several places when flood levels permit. The long journey times and periods during which the villages are accessible by road have an enormous impact on development in the region, limiting access to healthcare, markets and education. A funding organisation has offered financial support for the construction of the rural road and river crossing network.

Transition of community to client. The large scale of the overall community group means that the participative design would need to interact with individuals at the village level. Early village-level meetings would be necessary to inform individual communities about the parameters of the project, for example the available budget. At these meetings, a representative to a panel from each village (or representatives from multiple groups with each village e.g. youths, elders, men, women) could be elected to participate in regular meetings with the design team to develop the design. For final acceptance of a design solution, a community-wide vote would not be feasible (owing to the large number of individuals involved). Instead, the potential design solutions could be presented in each village by the design team; a standard for acceptance of the design could be voted for by a majority of those present in the meetings in each of the villages. While it would be key to avoid the traditional tribal leadership in every stage, the traditional leaders would be likely to prefer a more symbolic role in decision-making, since in the (often fractious) community, responsibility for controversial decisions is often avoided rather than sought out.

Community-specific needs identification. The area is poorly mapped, so significant outreach work would be required to visit all of the villages in the area, collecting information using focus groups or communal meetings on population data, seasonal road conditions and transport habits and requirements.

Iterative design process. The road design would be complex, requiring assessment of multiple factors including optimal location for a river crossing and other routing questions. The design team and the elected representatives would need to meet on multiple occasions to discuss options, constraints and seek consensus. The critical design decision to be taken might be the location of the principal river crossing. While the representatives would probably initially adopt self-interested positions in the negotiation, it should be possible over time to reach consensus on the optimum position for the crossing, with the design team providing recommendations in terms of efficient location and technical feasibility, since the benefits for each village of having any crossing would outweigh the disadvantages of conceding its location in a less-convenient position. The village representatives would have the responsibility of communicating progress on the design to their community, and negotiating with their community to ensure that any commitments made in terms of contributions to the capital cost, labour cost, operation or maintenance were realistic and acceptable. These individuals could also aid the design team in communicating the final proposed design, and the rationale behind it, to their villages in the design acceptance meetings.

\subsubsection{Arsenic-safe drinking water sources in rural villages, Bangladesh}

Context. Shallow ground water in Bangladesh is tainted with arsenic in much of the country, leading to a very significant problem with arsenic poisoning. Arsenic-safe drinking water can be provided by switching to a deep aquifer or by treating the water through oxidation and filtration. The technologies for providing safe drinking water (even when subsidised) are too expensive for the vast majority of households in rural areas and must therefore be provided at a community level.

Transition of community to client. Prior safe drinking water projects in the area have failed to achieve their objective of providing drinking water to a community as rich or influential members of the community have managed to co-opt the process and have the subsidised wells installed in their own compounds, where they are then unavailable for community use. Taking decisions at a community meeting where different socioeconomic groups and both genders are represented is believed to lead to more equitable and efficient outcomes. The relatively small size of the communities - typically several hundred households - means that decisions could be taken either by majority or by unanimous agreement at community meetings.

Community-specific needs identification. This could be achieved through social mapping of the communities - recording numbers of households, community structure, existing safe and unsafe drinking water options, and possible locations for safe water technologies (defined by available space, elevation (above floodline) and available drainage).

Iterative design process. Sites for safe drinking water options could be proposed by the design team using simple criteria of 
Engineering Sustainability

Volume 164 Issue ES1
An 'engineer-client' framework

for participation in community-

scale infrastructure projects

Mulligan, Tompsett and Guthrie public, technically appropriate spaces where need for a safe drinking water source was greatest within the community. This proposal could form a baseline for discussion, improvements and eventually acceptance at the community-wide meeting. Having a baseline design of wells that are installed in public spaces further protects the decision-making process from cooption, since changes to the proposed sites - for example, to a private site that is more accessible in terms of distance to more households - must then be justified by the individuals wanting to make those changes to the rest of the community.

\section{Discussion}

This conceptualisation of the participative design process is intended to clarify objectives and emphasise the areas where skills developed in the traditional engineer-client relationships are relevant in the development context. However, this framework also raises, or leaves unanswered, several important questions, which are discussed in the following sections.

\subsection{Moving back the boundary}

The framework described in this paper has conceptualised a transition at which the beneficiary is accorded the status of client. One of the key features of projects that successfully implement participative methods is that beneficiaries are involved in a meaningful way as early as possible in the process. A first implication suggested by this is that the boundary at which the beneficiary becomes the client should be pushed back in time (and in project stage) as far as possible: that is, that the project definition should be as open as possible when the community takes over decision-making control. A second implication is that community input should be incorporated even before this stage, as the initial parameters of the project are defined. While this is unlikely to involve community-specific issues, it suggests a need for consultation with focus groups and representatives from communities throughout the region as early as possible in project design.

NGOs, for example, could work towards these goals through long-term engagement with communities over repeated projects, while local government (where the cycles of campaigning and election permit) could incorporate community input into long-term project and budget planning.

\subsection{Financing: who pays for participation?}

The participative process requires significant input on the part of the community in terms of time and effort, and in some cases financial cost as well, for example where community members need to pay transport costs to participate in meetings, or when they sacrifice other opportunities to earn income in order to participate. The returns to this investment for the community are improvements in the quality of the project realised. However, those members of the community who are most active in the participative process bear a greater part of the cost. A separate, but related question therefore is assessing whether there is a need for community members to be compensated for the time that they invest in the participative process, which may be considerable, especially where community representatives are required to attend multiple meetings throughout a relatively complex design process. Again, there are probably no right answers, but this is an important issue to consider and discuss. The default assumption that compensation for participation is always inappropriate is likely, among other effects, to reduce the number of people willing to participate, to exclude community members who cannot afford the time, and to reduce incentives to participate for community members who must overcome social barriers to their participation (particularly women).

An effective participative process also requires significant time and effort on the part of the funding organisation and design team. This strongly suggests that successful implementation of a participative process requires the associated time and costs to be built into the budget and project schedule. Participative processes can be very time-consuming; indeed, they can often constitute the major activity of project staff, which is typically the major cost associated with increasing the level of participation. However, it seems difficult to offer a reliable rule of thumb for how much time or budget should be allowed, given the variety of projects that are discussed here. For largescale projects which repeat the same process in many different communities (such as the Bangladesh case study discussed in the previous section), a strong case can be made for piloting the participative process designed, both to identify potential problems and to verify the appropriate amount of time and hence budget required.

Community contributions (or user fees) are often seen as an integral part of the participative process, and are often claimed to ensure 'buy-in' and 'ownership' from the community. The effectiveness of this strategy may depend strongly on the context; an informal development in South Asia is likely to have very different constraints on cash availability than a rural, subsistence farming community in Africa. The issue of determining effective, affordable levels of community contributions should probably be treated separately from the question of how to achieve participation in decision-making, and, critically, participation in decision-making should never be seen as a way of ensuring that communities will automatically contribute financially. Full life-cycle project costs need to be explicitly budgeted for from the start of the project - whether this includes user contributions or not - and form part of the design package that is accepted by the community.

Similarly, community labour contributions must be carefully considered and negotiated; while these kinds of community 
Engineering Sustainability

Volume 164 Issue ES1
An 'engineer-client' framework

for participation in community-

scale infrastructure projects

Mulligan, Tompsett and Guthrie contributions may have a positive impact on the project, their appropriateness will depend on how successfully the whole community has been represented in earlier project stages. The engineer should be particularly careful to avoid situations where elites make demanding commitments on behalf of poorer members of the community, when elite members have no intention of participating in the labour involved. In extreme cases, community labour can act as a regressive tax on the poor (see, for example, Bowen, 1986).

\subsection{Limits of applicability of framework}

The framework outlined in this paper has been limited to a specific subset of projects: those in which a geographically bounded community is explicitly the primary beneficiary. However, 'participative approaches' are of course often recommended or even required by donors on projects that do not meet this description. An example might be a road construction project that connects two cities, the beneficiaries of which include: the populations of the two cities, communities of smaller settlements along the proposed route, temporary communities which are established during the construction of the road and future communities which may be established once the road connection is in place. In these cases, a clear analysis of rights over decision-making control is required to understand where fully participative approaches can be implemented. Where a community has essentially no decision-making power in the process, it is doubtful whether participative approaches beyond information gathering are meaningful.

Similarly, projects where the community is not the beneficiary at all - such as where a community is relocated during the process of dam construction - raise similar questions, particularly if the community does not have the right to reject relocation. The framework described here may, however, be of some limited use in mitigating the damage done to communities through relocation - for example, where communities are allotted some decision-making power in how relocation takes place.

\section{Conclusion}

This paper has laid out a framework for achieving successful participation in community-scale infrastructure development projects while incorporating technical knowledge from external experts. The framework, based on a parallel between the engineer-client relationship in a traditional setting and the engineer-community relationship in a development context, has laid out the similarities, and important differences, between the two settings. It provides an outline to support the development of local, context-specific solutions by setting out clear objectives and problem definitions, in recognition of the fact that there is no universal recipe for success. It also illustrates the areas in which client-management skills developed in a traditional context can be adapted to be effective in a participatory context.

The context for the framework set out in this paper is the debate surrounding the value of participation, and how best to realise its potential benefits. The framework set out here reflects the belief that successful participation in decision-making should not be dependent on a serendipitous combination of cooperative, egalitarian communities and talented engineers and facilitators. Instead, by setting clear objectives and guidelines for the creation of a decision-making structure and process that maintains both real influence for the community and real agency for the engineer, tailored, context-appropriate structures for participation can be developed and successfully applied anywhere.

\section{REFERENCES}

Anyaegbunam C, Mefalopulos P and Moetsabi T (2004) Participatory Rural Communication Appraisal: Starting with the People: A Handbook, 2nd edn. Food and Agriculture Organzation of the United Nations, Rome.

Bowen JR (1986) On the political construction of tradition: Gotong Royong in Indonesia. Journal of Asian Studies 45(3): 545-561.

Dasgupta A and Beard VA (2007) Community driven development, collective action and elite capture in indonesia. Development and Change 38(2): 229-249.

FAO (Food and Agriculture Organization) (2003) Chapter 9: training module on participatory community monitoring and evaluation. A Handbook for Trainers on Participatory Local Development: The Panchayati Raj Model in India. Food and Agriculture Organization, Rome.

Isham J, Narayan D and Pritchett L (1995) Does participation improve performance? Establishing causality with subjective data. World Bank Economic Review 9(2): 175200.

Khwaja Al (2004) Is increasing community participation always a good thing? Journal of the European Economic Association 2(2/3). Papers and Proceedings of the Eighteenth Annual Congress of the European Economic Association, 427-436.

Kleemeier E (2000) The impact of participation on sustainability: an analysis of the Malawi Rural piped scheme program. World Development 28(5): 929-944.

Mansuri G and Rao V (2004) Community-based and-driven development: a critical review. World Bank Research Observer 19(1): 1-13.

Norton A, Bird B, Brock K, Kakande M and Turk C (2001) A Rough Guide to PPAs: Participatory Poverty Assessment: An Introduction to Theory and Practice. Overseas Development Institute, London.

Sara J and Katz T (1997) Making Rural Water Sustainable: 
Report on the Impact of Project Rules. UNDP - World

Bank Water and Sanitation Program, Washington, D.C.

Vernooy R, Qiu S and Jianchu X (2003) Voices for Change:

Participatory Monitoring and Evaluation in China.

International Development Research Centre, Canada.

Welle K (2006) Water Aid Learning for Advocacy and Good

Practice: Water and Sanitation Mapping in Nepal. Water Aid Report.

World Bank (1996) World Bank Participation Sourcebook.

World Bank, Washington D.C.

\section{WHAT DO YOU THINK?}

To discuss this paper, please email up to 500 words to the editor at journals@ice.org.uk. Your contribution will be forwarded to the author(s) for a reply and, if considered appropriate by the editorial panel, will be published as discussion in a future issue of the journal.

Proceedings journals rely entirely on contributions sent in by civil engineering professionals, academics and students. Papers should be 2000-5000 words long (briefing papers should be 1000-2000 words long), with adequate illustrations and references. You can submit your paper online via www.icevirtuallibrary.com/content/journals, where you will also find detailed author guidelines. 